\title{
Successful therapy of excoriated acne with Nd:YAG laser: a case report
}

\author{
Vesna Tlaker $^{1 凶}$
}

\begin{abstract}
Excoriated acne is a difficult challenge in daily practice. Patients generally fail to follow the most important measure: not to "clean" and manipulate their lesions. Because the literature tends to emphasize the mental aspect of this condition, patients with excoriated acne may be quickly classified as psychosomatic or even psychiatric cases, and dermatologists may be overlooking opportunities to help. This report presents the case of a young woman with excoriated acne and anorexia nervosa, treated with a combination of 1,064 $\mathrm{nm} \mathrm{Nd:YAG} \mathrm{laser,} \mathrm{standard} \mathrm{acne} \mathrm{topical} \mathrm{therapy,} \mathrm{and} \mathrm{a} \mathrm{reassuring,} \mathrm{non-judgmental} \mathrm{approach.} \mathrm{The} \mathrm{therapy} \mathrm{resulted} \mathrm{in}$ complete remission after 2 months, which has remained stable during 3 years of follow-up.
\end{abstract}

Keywords: excoriated acne, acne laser therapy, Nd:YAG laser

Received: 17 April 2017 | Returned for modification: 24 May 2017 | Accepted: 25 June 2017

\section{Introduction}

Some girls and young women, as well as occasional male patients, are so distressed by what an outside observer perceives as minimal acne that they literally attack their lesions (1). The condition is referred to as excoriated acne, acne excoriata or acne excoriée (des jeunes filles). The clinical appearance is characterized by excoriated areas of inflammation with superficial crusting (2). The manipulation of lesions usually includes fingernails as well as a whole armamentarium of instruments (e.g., tweezers, scissors, nail files, pins, enlarging and illuminating mirrors, etc.). The manipulation produces far more visible skin lesions, slower healing, and more scarring than the natural course of the disease would.

Excoriated acne is believed to be a subtype of pathological skin picking with lesions generally limited to the face (3) in which the sufferer compulsively picks real or imagined acne lesions (4). Bodily focused anxiety or even body dysmorphic disorder can be associated with and participate in the pathophysiology of excoriated acne (3). The patients often complain of significant pruritus in the lesions (4).

There are no specific treatment guidelines for excoriated acne, and the condition is not mentioned as a separate entity in the current European or American guidelines on treatment of acne (5, 6). Throughout the literature, the psychological component of the disease is emphasized; however, there has been a report on allergy as a cause of itch and skin picking in a woman diagnosed with excoriated acne, suggesting that allergy should be considered and ruled out (7).

Treatment of excoriated acne can be difficult. Topical treatment tends to irritate the skin and aggravate the problem (4). The importance of not picking needs to be emphasized. If active acne is evident, some recommendations suggest an aggressive approach to treatment $(4,8)$. By reducing the number of inflammatory lesions, the regimen leaves the patient with fewer spots to tamper with (4).

Therapy with certain psychoactive drugs has been described as successful, including trifluoperazine hydrochloride, pimozide, olanzapine, lithium, doxepin, fluoxetine, and sertraline, as well as cognitive psychotherapy, hypnosis, and habit-reversal techniques (4, 8-13).
If there are no evident acne lesions, some recommendations suggest only a careful and sensitive psychosocial approach to the patient with verbal, non-prescription-based treatment to somehow sufficiently reassure the patient that she is able to stop picking (1). Laser can reduce scarring due to excoriated acne (13).

\section{Case report}

The patient was a 23-year-old female that presented with excoriated papules and shallow ulcers on the face (Figs. 1-3). She had been struggling for several years with mild facial acne, consisting predominantly of papules and comedos. She had tried an endless number of non-prescription measures against acne, including topical products and procedures performed by a facialist, including mild alpha-hydroxy acid peels. The patient had a meticulous skincare routine. Any minimal skin lesion bothered her endlessly and relief was only achieved by removing the lesion by squeezing it out or "cleaning" it with the fingers, tweezers, or some other instrument. She had also regularly used a magnifying mirror to spot any lesions.

The patient also had anorexia nervosa and weighed $37 \mathrm{~kg}$ (BMI 13.6). She was not menstruating; she had only had two periods in her life. She reported no other health issues. Otherwise, the patient was a very bright and intelligent university student, completely aware that her skin "cleaning" represented the cornerstone of her problem.

Upon her first visit, the patient was given sufficient time to discuss her condition and express her concerns. She was reassured that her condition was not understood as an act of deliberate self-harm, but as a consequence of the only thing that helped her alleviate her symptoms: "cleaning" her skin and removing the lesions. In no direct or indirect way was it suggested that her skin condition might be a purely psychological or even psychiatric issue, and she was reassured that we would do our best to help bring the breakouts of her facial lesions under control. The issue of her anorexia was not raised. However, she was informed clearly that any scratched or picked lesions take much longer to heal, and that in order to recover quickly she was supposed not to "clean" the lesions. She was advised to keep her magnifying mirror, 
scissors, and tweezers away. The patient was presented with all the possible therapeutic measures for mild to moderate acne, including topicals, laser, and systemic therapies. The patient chose to first try the topical therapy and laser.

She was prescribed azelaic acid cream bid and fusidic acid cream bid. In addition, we performed a series of therapies with a 1,064 nm Nd:YAG laser (SP Dynamis, Fotona, Slovenia). Every session included three full-face passes with the S11 scanner, 6 $\mathrm{mm}$ spot, $25 \mathrm{~ms}, 40-45 \mathrm{~J} / \mathrm{cm}^{2}$. During the procedure, the skin was cooled with a Zimmer Cryo 6 device. Six sessions were performed, one every 2 weeks. The first two sessions did not result in much visible improvement, but gradually the patient noticed that each session alleviated the existing lesions and reduced the severity of new outbreaks. After 2 months, the remission was complete with only a few residual hyperpigmentations, which eventually faded completely (Figs. 4-6).

The patient is still in remission after 3 years of follow-up. She returns to the office every 2 or 3 months for one session of laser therapy whenever she feels there is an emerging outbreak, and each session of laser therapy induces a 2- to 3-month remission. The patient continues to use azelaic acid cream daily.

\section{Discussion}

Excoriated acne is a notoriously difficult condition to treat. Even before the patient says her first word at the door, many dermatologists recognize the condition and may suspect that therapy would fail because the patient would be unable to follow the only necessary rule to improve the skin: do not scratch.

Journal publications on excoriated acne are few, and dermatological textbooks place much emphasis on the psychological component. In clinical practice, and particularly if the physical findings consist mainly of artifacts, patients with excoriated acne might be quickly classified as psychosomatic or even psychiatric cases. The patients generally do not perceive themselves as such, and they wander from one dermatologist to the other. In an extensive literature search, only one report was found urging dermatologists to consider and rule out a somatic problem in excoriated acne (7). Possible somatic issues might deserve more attention in excoriated acne in the future. However, in our patient, the clinical diagnosis of excoriated acne was based on physical findings of artifacts on the background of mild facial acne, and no diagnostic procedures were considered necessary.
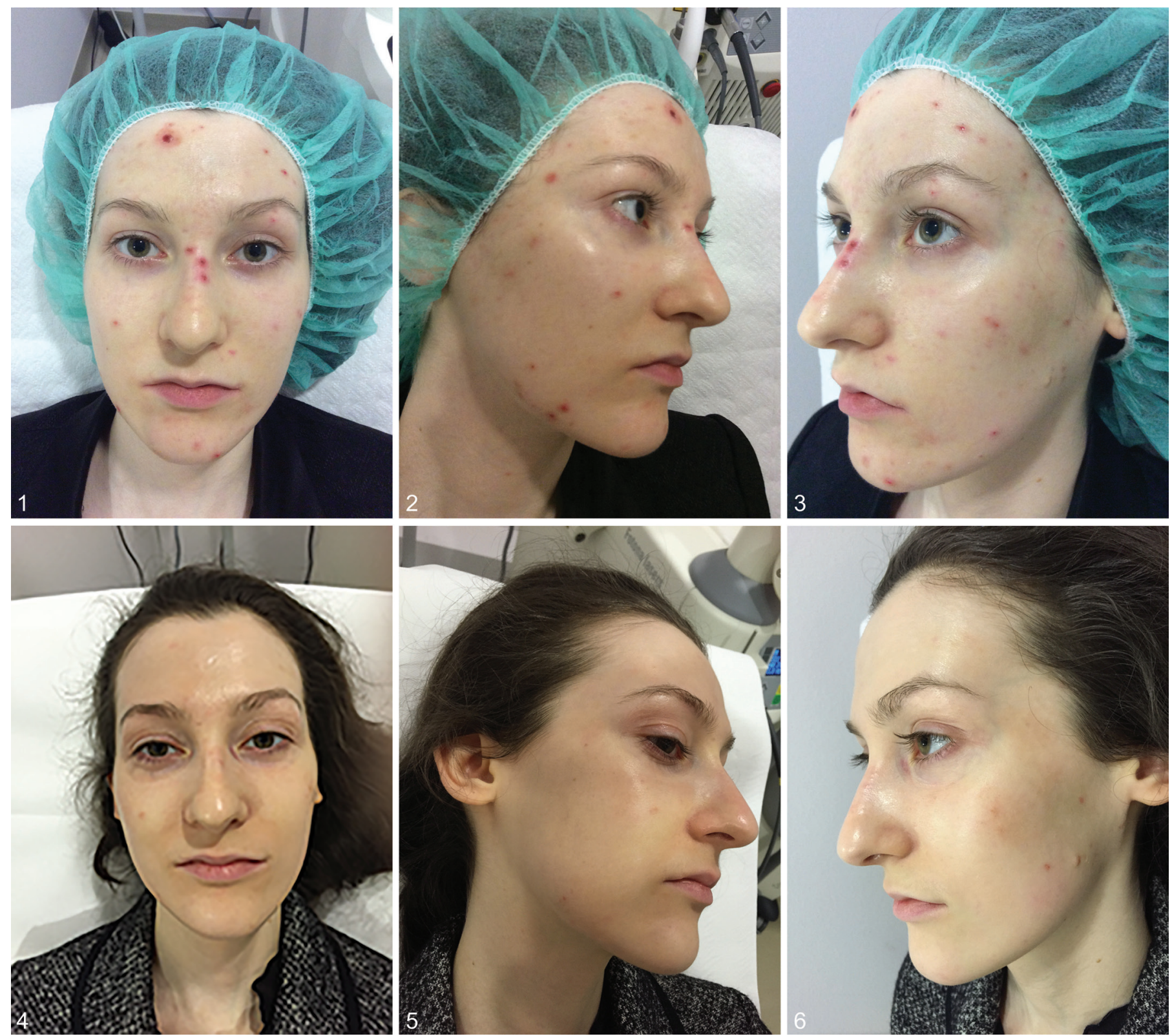

Figures 1-6 | (1-3) The patient before therapy. (4-6) The patient after five sessions of Nd:YAG laser therapy and 2 months of topical treatment with azelaic and fusidic acid. 
With this case report, the author would like to emphasize two issues. First, a non-biased and non-judgmental approach to a patient with two difficult psychological issues (anorexia nervosa and excoriated acne) might have been one of the components of successful therapy. The patient was never criticized for her behavior or given patronizing advice; as a partner in the therapeutic process, she was fully provided with explanations of the mecha-

\section{References}

1. Plewig G. Acne and rosacea. In: Burgdorf WHC, Plewig G, Wolff HH, Landthaler M, eds. Braun-Falco's dermatology. 3rd ed. Heidelberg: Springer; 2009: p. 1005.

2. Cunliffe WJ, Gollnick HPM. Acne: diagnosis and management. London: Martin Dunitz; 2001.

3. Gieler U, Consoli SG, Tomás-Aragones L, Linder DM, Jemec GB, Poot F, et al. Selfinflicted lesions in dermatology: terminology and classification-a position paper from the European Society for Dermatology and Psychiatry (ESDaP). Acta Derm Venereol. 2013;93:4-12.

4. Layton AM. Disorders of the sebaceous glands. In: Burns T, Breathnach S, Cox N, Griffiths C. Rook's textbook of dermatology. Oxford: Wiley; 2010. p. 43.1-43.74.

5. Nast A, Dréno B, Bettoli V, Degitz K, Erdmann R, Finlay A, et al. European evidence-based ( $\left.\mathrm{S}_{3}\right)$ guidelines for the treatment of acne. J Eur Acad Dermatol Venereol. 2012;26 Suppl 1:1-29.

6. Zaenglein AL, Pathy AL, Schlosser BJ, Alikhan A, Baldwin HE, Berson DS, et al. Guidelines of care for the management of acne vulgaris. J Am Acad Dermatol. 2016;74:945-73.

7. Kränke B, Brabek E, Derhaschnig J, Aberer W. Acne excoriate-look for allergy! Dermatology. 2001;203:256-7. nism of her condition.

Second, the Nd:YAG 1,064 nm laser therapy reduced and eventually completely prevented the appearance of primary inflammatory lesions. There are some reports of successful therapy of acne with this type of laser (14); however, this is the first report of successful therapy of excoriated acne with this type of laser therapy.

8. Koo J, Lee CS. Psychocutaneous diseases. In: Bolognia JL, Jorizzo JL, Rapini RP. Dermatology. 2nd ed. New York: Elsevier, 2008: pp. 109-10.

9. Chuh A, Wong W, Zawar V. The skin and the mind. Aust Fam Physician. 2006;35: 723-5.

10. Sharma H. Psychogenic excoriation responding to fluoxetine: a case report. J Indian Med Assoc. 2008;106:245, 262.

11. Shenefelt PD. Using hypnosis to facilitate resolution of psychogenic excoriations in acne excoriée. Am J Clin Hypn. 2004;46:239-45.

12. Gupta MA. Emotional regulation, dissociation, and the self-induced dermatoses: clinical features and implications for treatment with mood stabilizers. Clin Dermatol. 2013;31:110-7.

13. Bowes LE, Alster TS. Treatment of facial scarring and ulceration resulting from acne excoriée with $585-\mathrm{nm}$ pulsed dye laser irradiation and cognitive psychotherapy. Dermatol Surg. 2004;30:934-8.

14. Mohamed EE, Tawfik K, Elsaie M. Intense pulsed light versus 1,064 long-pulsed neodymium: yttrium-aluminum-garnet laser in the treatment of facial acne vulgaris. J Clin Diagn Res. 2016;10:WC01-3. 